\title{
sciendo

\section{Economic Performance of Net-Zero Energy Community under Reward-Penalty Mechanism Considering PV System Reliability}

\author{
Yuehong $\mathrm{LU}^{1,2 *}$, Zafar $\mathrm{KHAN}^{2,3}$, Hasan GUNDUZ ${ }^{2}$, Wei WANG ${ }^{4}$, \\ Jianing $\mathrm{LI}^{2}$, Xiao-Ping $\mathrm{ZHANG}^{2}$ \\ ${ }^{1}$ Department of Civil Engineering and Architecture, Anhui University of Technology, Ma'anshan, \\ 243002, China \\ ${ }^{2}$ Department of Electronic, Electrical and Systems Engineering, University of Birmingham, UK \\ ${ }^{3}$ Electrical Power Engineering, Mirpur University of Science and Technology, Mirpur (A.K.), Pakistan \\ ${ }^{4}$ Modeling and Simulation of Structures, Bauhaus University Weimar, Weimar, Germany
}

\begin{abstract}
Economic performance of net-zero energy building/community (ZEB/ZEC) is an important factor that affects potential investors' decision on installing renewable energy systems (RES). A reward-penalty mechanism (RPM) is proposed for accelerating the development of zero energy communities, which is developed without considering the reliability effect from RES generation. However, an investigation is deserved for the reliability effect of RES on building economic performance. A case study is therefore conducted based on an assumed community consisting of 20 family houses, in which the electricity load was collected by the smart meter for more than one year. The results show that the proposed RPM works efficiently under an ideal condition, while the costs of the community and its buildings are greatly increased when the effect of PV system reliability is considered. Specifically, the total cost of the community under 1.0ZEC design is $5005 \mathrm{USD} / \mathrm{yr}$ in the first year, which increases to $11341 \mathrm{USD} / \mathrm{yr}$ in the $25^{\text {th }}$ year. By contrast, the total cost of the community under 1.2ZEC design is $5243 \mathrm{USD} / \mathrm{yr}$ in the first year and increases to 9607 USD/yr in the $25^{\text {th }}$ year. It is believed that the results of this study can provide a progressive perspective for scheme makers and building owners in terms of its economic benefit. Development of enhanced RPM by considering system reliability will be investigated in our future work.
\end{abstract}

Keywords - Economic performance; PV system; reliability; reward-penalty mechanism; net-zero energy building/community

\section{Nomenclature \\ PV Photovoltaic \\ RES Renewable energy system}

RRM Reward-penalty mechanism

ZEB/ZEC Net-zero energy building/community

Ebec,n $\quad$ Energy consumption of building of building $\mathrm{n} \quad \mathrm{kWh} / \mathrm{yr}$

* Corresponding author.

E-mail address: luyuehongtuzi@163.com

(C2019 Yuehong Lu, Zafar Khan, Hasan Gunduz, Wei Wang, Jianing Li, Xiao-Ping Zhang.

This is an open access article licensed under the Creative Commons Attribution License (http://creativecommons.org/

licenses/by/4.0), in the manner agreed with Sciendo. 


\begin{tabular}{|lll|}
\hline$E_{\mathrm{cec}}$ & Energy consumption of a community & $\mathrm{kWh} / \mathrm{yr}$ \\
$C_{\mathrm{io}}$ & Initial cost and operation cost & $\mathrm{USD} / \mathrm{yr}$ \\
$C_{\mathrm{rp}}$ & Reward-penalty value & $\mathrm{USD} / \mathrm{yr}$ \\
$T_{\mathrm{C}}$ & PV module temperatures in the current hour & ${ }^{\circ} \mathrm{C}$ \\
$T_{\mathrm{STC}}$ & PV module temperatures under standard test conditions & ${ }^{\circ} \mathrm{C}$ \\
$T C$ & The total cost of a community & $\mathrm{USD} / \mathrm{yr}$ \\
$T C_{n}$ & The total cost of building $n$ & $\mathrm{USD} / \mathrm{yr}$ \\
$R_{\mathrm{zec}}$ & The level of zero energy community & \\
$\lambda_{\mathrm{r}}$ & Failure rate & $1 / \mathrm{h}$ \\
$\mu_{\mathrm{r}}$ & Repair rate & $1 / \mathrm{h}$ \\
$\lambda_{\mathrm{F}}$ & Degradation rate of the component & $1 / \mathrm{h}$ \\
$T_{\mathrm{W}}$ & Life time of the component & $\mathrm{year}(\mathrm{yr})$ \\
$f_{\mathrm{pv}}$ & Derating factor of PV system & $\%$ \\
$k_{\mathrm{p}}$ & The temperature coefficient of PV generation & $\% /{ }^{\circ} \mathrm{C}$ \\
$I_{\mathrm{T}}$ & Solar radiation on the surface of the PV array & $\mathrm{kW} / \mathrm{m}^{2}$ \\
$I_{\mathrm{S}}$ & Solar radiation under standard test & $\mathrm{kW} / \mathrm{m}^{2}$ \\
$i$ & The time of a year, $1 \leq I \leq 8760$ & $\mathrm{~h}$ \\
\hline
\end{tabular}

\section{INTRODUCTION}

The increasing electricity consumption is a significant contributory factor associated with problems both in the areas of energy conservation and environmental protection [1], [2]. In this context, the construction sector has been recognized to be responsible for the high energy consumption and environmental degradation [3], [4]. To solve this problem, sustainable buildings, e.g., green buildings and low/net-zero energy buildings, have been advocated as a guiding paradigm to sustainable development [5], [6].

Two questions, i.e., how to motivate owners to renovate their homes and increase energy efficiency and what business models should be used to implement economically viable and high-quality projects, were proposed based on a survey study of buildings in Latvia [7]. Incentive policy is a promising method that has been established worldwide to encourage the development of green buildings as project owners are driven to adopt green building practices. Generally, incentives can be defined as something that influence people to act in certain ways [8]. Usually, the government is responsible for administering the external incentives, in which the beneficiaries are handed a forced choice of meeting a specified green building related condition or requirement so as to benefit from this type of incentives [9]. The external incentive involves direct financial incentives and non-financial incentives, and the tax incentive is a popular financial incentive offered by the government, especially in the USA [10]. Although no direct costs are involved in non-financial incentives, they are actually financially rewarding because it saves owners' time by mitigating risk and process issues [11], [12]. The internal incentives involve human well-being related incentive, demand related incentive, gratifying incentive, persuasion and inspirational incentive, and this kind of incentives is a forced choice and beneficiaries are required to fulfil specified conditions or requirements before benefitting [13]. The gratifying incentives are an effective way of assessing the achievement of green buildings. The certification provides the owners with a 
feeling of gratification since their image and reputation are increased. For instance, the Green Builder logo of the Austin Green Building Program, Texas, US, helps participants increase their reputation and competition [14]. In the USA, the level of LEED certification (e.g. LEED Platinum, LEED Silver) is highly important for a new project in the Real Estate industry since it helps participants differentiate themselves from their competitors [15], [16]. A further investigation and comparative analysis of LEED projects can be identified in the literatures [17], [18].

For green society construction and sustainable development, the use of renewable energy resources has been accepted as a positive solution. A survey of current statues, problems and prospects was conduct on renewable energy development in Malaysia [19]. Substantial financial incentive policies, i.e. investment subsides, net metering schemes, and feed-in tariff, etc., mainly contribute to the widespread of renewable energy application [20], [21]. For instance, in the study of Banovac et al. [22], four most important regulatory functions ((licensing, monitoring, tariff setting and implementation, and customer protection) were used to define the regulatory mechanism with sufficient fidelity. The authors estimated that these functions together account for more than $80 \%$ of all regulatory activity. Li et al. [23] established a two-level decision sub-game led by the national government and compares the cost-saving effect before and after the application of Chinese Certified Emission Reduction scheme. A survey of impact models underlying 60 agri-environmental schemes in seven EU member states was conducted by Primdahl et al. [24], based on which the role of impact models at different stages in the agri-environmental schemes policy process can be identified. Although a growing body of research were identified to focus on how to make and adjust incentive mechanisms in the context of the technical innovation of renewables and the curtailment of incentive rates, few incentives are developed specifically for net zero energy building [25]. To address these problems, Lu et al. [25] introduced a penalty cost to ensure that a minimum total cost is located within a safety factor of 1.0 (i.e., 1.0ZEB). The results show that ZEB owners would pay only half of the original cost. And then they further investigated the effective of penalty cost using two segmented functions, which was demonstrated to work successfully in the case of Hong Kong zero carbon building [26].

However, no reward-penalty mechanism has been developed at a community level that aims to achieve zero energy community. In addition, the reliability of generation system can affect the power generation which may result in a great difference on expected economic performance for building owners. This study is therefore conducted to investigate the influence of the reliability of PV system on the economic cost of a community and its buildings under the developed reward-penalty mechanism.

\section{Development of ReWARd-Penalty Mechanism for a Community}

Fig. 1 shows the main procedure for developing and applying community-level RPM. In general, a community load level and the level of zero energy community are two key factors for the development of community-level RPM. Firstly, the hourly energy consumption profile from a community is required based on its historical energy consumption data. Then, PV system-driven zero energy community (ZEC) are divided into several levels, based on which the required PV system, annual initial cost as well as annual operation cost could be derived. Thus, the traditional annual cost of the community (i.e., $C_{\text {io }}$, initial cost and operation cost) can be fitted as a linear fitting formula, as shown in Eq. (1). A reward-penalty function Eq. (2) is introduced to follow a quadratic concave curve, enabling the cost-effective system selection for a community where a high PV system should be expected. Therefore, the total 
cost can be calculated in Eq. (3) based on Eq. (1) and Eq. (2). Given three conditions (i.e., the preference of scheme makers' decision, like Eq. (4)-(6)), the reward-penalty function can be solved. For instance, the ratio $\left(\varepsilon_{1}, \varepsilon_{2}\right)$ of the total cost to the initial \& operation cost at 0.0ZEC design and 1.0ZEC design, respectively; and the level of ZEC corresponding to the lowest total cost. Finally, the total cost $(T C)$ for the community under RPM is the sum of traditional annual cost $\left(C_{\mathrm{io}}\right)$ and reward-penalty value $\left(C_{\mathrm{rp}}\right)$.

$$
\begin{gathered}
C_{\mathrm{io}}=b_{1} \cdot R_{\mathrm{zec}}+c_{1}, \\
C_{\mathrm{rp}}=a_{2} \cdot R_{\mathrm{zec}}^{2}+b_{2} \cdot R_{\mathrm{zec}}+c_{2}, \\
T C=C_{\mathrm{io}}+C_{\mathrm{rp}}, \\
R_{\mathrm{rez}}=0.0, T C=\varepsilon_{1} \cdot C_{\mathrm{io}}, \\
R_{\mathrm{rec}}=1.0, T C=\varepsilon_{2} \cdot C_{\mathrm{io}}, \\
T C_{\min }=T C\left(R_{\mathrm{zec}}=1.0\right) .
\end{gathered}
$$

Thirdly, apply the RPM to the community and then obtain the corresponding total cost for different levels of zero energy community $\left(R_{\mathrm{zec}}\right)$. Therefore, the total cost is the accumulated cost of the entire buildings in the community. The last step is to allocate the cost to each building based on its load level, as shown in Eq. (7). Where, $T C_{n}$ is the allocated cost for building $n, E_{\mathrm{bec}, \mathrm{n}}$ and $E_{\mathrm{cec}}$ are the energy consumption of building $n$ and energy consumption of the community, respectively. It is assumed that the cost is allocated based on the level of building energy consumption.

$$
T C_{n}=T C \cdot \frac{E_{\mathrm{bec}, n}}{E_{\mathrm{cec}}}
$$




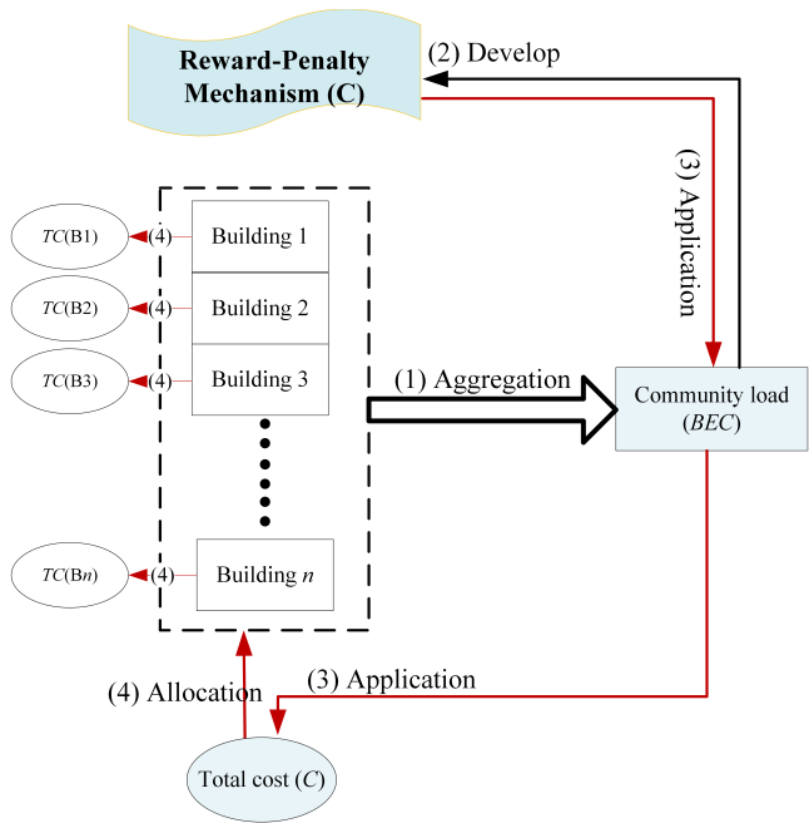

Fig. 1. Schematic diagram of community-level RPM.

\section{Reliability AnAlysis of PV System}

The representation of all possible states in a space state diagram is called Markov chain [27]. The states employed to define the reliability model of each generation unit are: " 1 " operating, " 2 " repairable failure and " 3 " obsolescence. The transitions rates are defined as: failure $\lambda_{\mathrm{r}}$, repair $\mu_{\mathrm{r}}$ and degradation $\lambda_{\mathrm{F}}$. Fig. 2 shows the model developed by Alvarez-Alvarado and Jayaweera [28], which is employed for PV system reliability analysis in this study. The degradation rate can be calculated by Eq. (8).

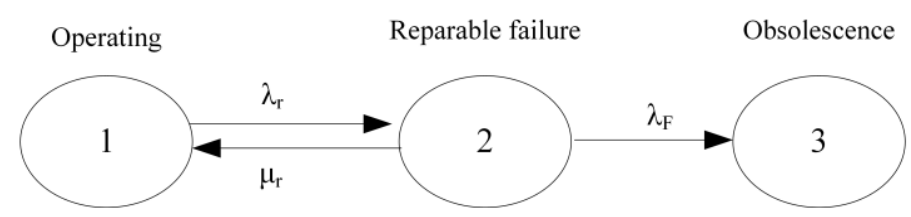

Fig. 2. Markov chain model considering aging effect [28].

$$
\lambda_{\mathrm{F}}=\frac{\lambda_{\mathrm{r}}+\mu_{\mathrm{r}}}{T_{\mathrm{W}} \cdot \lambda_{\mathrm{r}}-1} .
$$

The probability of being in each state can be mathematically determined from the stochastic matrix of transition states $H$. This matrix is the infinitesimal generator of dimensions $z \cdot z$, where $z$ is the total number of states [29]. 


$$
H=\left(\begin{array}{ccc}
-\lambda_{\mathrm{r}} & \lambda_{\mathrm{r}} & 0 \\
\mu_{\mathrm{r}} & -\mu_{\mathrm{r}} & \lambda_{\mathrm{F}} \\
0 & 0 & 0
\end{array}\right)
$$

Then, the probability vector of all possible states is determined by Eq. (10), where $v$ is the eigenvalues of $H^{\mathrm{T}}, v$ is the eigenvectors of $H^{\mathrm{T}}$ and $k$ is a constant given by the initial state; $T$ indicates the transpose of the matrix [30], [31].

$$
P(t)=\sum_{i=1}^{z} k_{i} v e^{-v_{i} t}
$$

where

$$
\begin{aligned}
& k_{1}=1 ; k_{2}=\frac{\lambda_{\mathrm{r}}+\lambda_{\mathrm{F}}+\mu_{\mathrm{r}}-a}{2 a} ; k_{3}=\frac{-\lambda_{\mathrm{r}}-\lambda_{\mathrm{F}}-\mu_{\mathrm{r}}-a}{2 a} ; a=\sqrt{-4 \lambda_{\mathrm{r}} \lambda_{\mathrm{F}}+\left(\lambda_{\mathrm{r}}+\lambda_{\mathrm{F}}+\mu_{\mathrm{r}}\right)^{2}}, \\
& v_{1}=0 ; v_{2}=\frac{-\lambda_{\mathrm{r}}-\mu_{\mathrm{r}}-\lambda_{\mathrm{F}}-a}{a} ; v_{3}=\frac{-\lambda_{\mathrm{r}}-\lambda_{\mathrm{F}}-\mu_{\mathrm{r}}+a}{a}, \\
& v=\left(\begin{array}{ccc}
0 & \frac{\left(\lambda_{\mathrm{r}}-\lambda_{\mathrm{F}}-\mu_{\mathrm{r}}+a\right)\left(\lambda_{\mathrm{r}}+\lambda_{\mathrm{F}}+\mu_{\mathrm{r}}+a\right)}{4 \lambda_{\mathrm{F}} \lambda_{\mathrm{r}}} & \frac{\left(-\lambda_{\mathrm{r}}-\lambda_{\mathrm{F}}-\mu_{\mathrm{r}}-a\right)\left(\lambda_{\mathrm{r}}+\lambda_{\mathrm{F}}+\mu_{\mathrm{r}}-a\right)}{4 \lambda_{\mathrm{F}} \lambda_{\mathrm{r}}} \\
0 & \frac{-\lambda_{\mathrm{r}}-\lambda_{\mathrm{F}}-\mu_{\mathrm{r}}-a}{2 \lambda_{\mathrm{F}}} & \frac{-\lambda_{\mathrm{r}}-\lambda_{\mathrm{F}}-\mu_{\mathrm{r}}+a}{2 \lambda_{\mathrm{F}}} \\
1 & 1 & 1
\end{array}\right) .
\end{aligned}
$$

A measure of reliability is the availability of the component, and it is defined as the sum of the probabilities of being in operating state, as shown in Eq. (14). By considering the aging effect of PV system, the availability of PV system is reduced as time passes, as displayed in Fig. 3 and Table 1.

$$
A(t)=k_{1} v_{11} e^{-v_{1} t}+k_{2} v_{12} e^{-v_{2} t}+k_{3} v_{13} e^{-v_{3} t}
$$




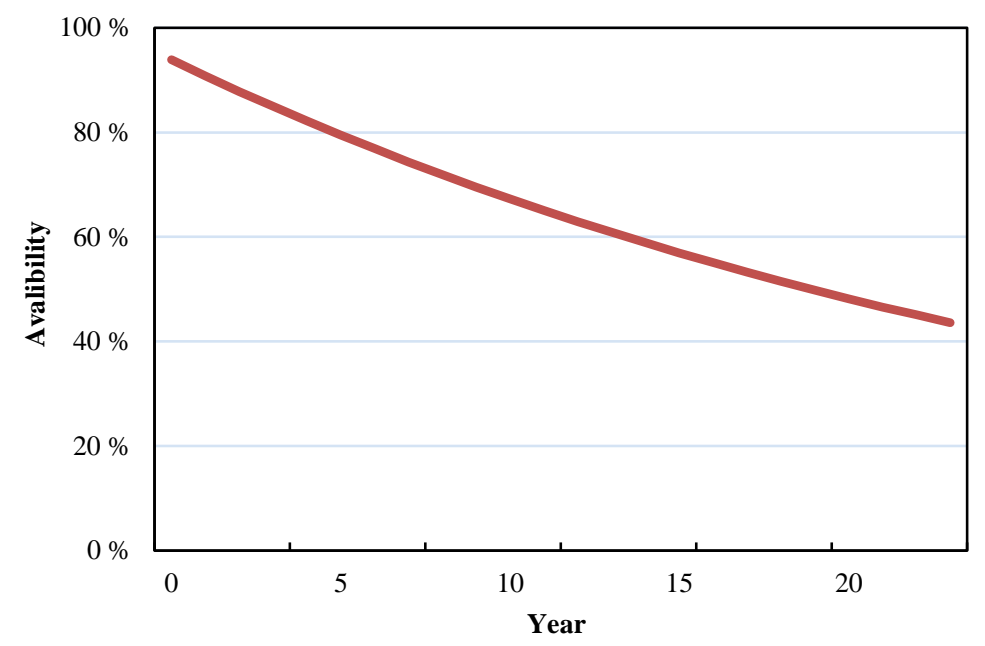

Fig. 3. The effect of operation year on availability of PV system.

TABLE 1. AVAILABILITY OF PV SYSTEM FOR 25 YEARS

\begin{tabular}{llllllllllllll}
\hline Year & $\mathbf{1}$ & $\mathbf{3}$ & $\mathbf{5}$ & $\mathbf{7}$ & $\mathbf{9}$ & $\mathbf{1 1}$ & $\mathbf{1 3}$ & $\mathbf{1 5}$ & $\mathbf{1 7}$ & $\mathbf{1 9}$ & $\mathbf{2 1}$ & $\mathbf{2 3}$ & $\mathbf{2 5}$ \\
\hline Availability & 0.939 & 0.878 & 0.822 & 0.769 & 0.719 & 0.673 & 0.629 & 0.589 & 0.551 & 0.515 & 0.482 & 0.451 & 0.422 \\
\hline
\end{tabular}

\section{Case Study and Result Analysis}

\subsection{Description of Case Study}

The proposed RPM strategies are investigated based on the electricity consumption of a community consisting of a randomly selected 20 family-houses in Ireland [32]. The data set are collected from the smart meter data with half-hourly records for more than one year [33]. In this study, the temperature and solar energy in Dublin, Ireland are used to evaluate PV generation. The average temperature and irradiation on optimally inclined plate in Dublin (longitude is $53^{\circ} 26^{\prime} 10^{\prime \prime}$, latitude is $6^{\circ} 15^{\prime} 53^{\prime \prime}$ ) are displayed Table 1 , where, the average annual temperature and available irradiation on optimally inclined plate are identified to be $10.2{ }^{\circ} \mathrm{C}$ and $3020 \mathrm{Wh} / \mathrm{m}^{2} /$ day. The range of the annual building electricity load is observed to between 1476 and $11191 \mathrm{kWh} / \mathrm{yr}$, and the 20 buildings are arranged according to its load as shown in Fig. 4. A summary of the entire community electricity load is presented in Fig. 5, it is observed that the load of the entire community ranges from 8000 to $12000 \mathrm{kWh} / \mathrm{month}$, and it is $120567 \mathrm{kWh}$ for a year.

PV array is assumed for supplying power to the grid-connected community, which takes into account the effect of temperature as calculated in Eq. (15), where $E_{\mathrm{pv}, \mathrm{i}}$ is the PV generation per $\mathrm{kW}$ at the hour $i, f_{\mathrm{pv}}$ is the PV derating factor $(\%)$ and is selected to be $0.9, I_{\mathrm{T}, \mathrm{i}}$ is the solar radiation on the surface of the PV array $\left(\mathrm{kW} / \mathrm{m}^{2}\right)$ at the time $i$, and $I_{\mathrm{S}}$ is the radiation under standard test conditions $\left(1 \mathrm{~kW} / \mathrm{m}^{2}\right)$. The temperature coefficient of power is represented by $k_{\mathrm{p}}\left(\% /{ }^{\circ} \mathrm{C}\right), T_{\mathrm{C}}$ and $T_{\mathrm{STC}}$ are the $\mathrm{PV}$ module temperatures in the current hour $\left({ }^{\circ} \mathrm{C}\right)$ and under standard test conditions $\left(25^{\circ} \mathrm{C}\right)$. The PV efficiency is $18 \%$ under the standard test condition. 


$$
E_{\mathrm{pv}, i}=f_{\mathrm{pv}} \frac{l_{\mathrm{T}, i}}{l_{\mathrm{s}}}\left[1+k_{\mathrm{p}}\left(T_{\mathrm{C}, i}-T_{\mathrm{STC}}\right)\right] .
$$

The zero-energy level of a community $\left(R_{\text {zec }}\right)$ is defined as the ratio of on-site PV energy generation $\left(E_{\mathrm{pv}}\right)$ to its energy consumption, as shown in Eq. (16), a higher value of $R_{\text {zec }}$ represents a higher zero energy level of the community.

$$
R_{\mathrm{zec}}=\frac{E_{\mathrm{pv}}}{E_{\mathrm{cec}}} .
$$

TABLE 2. AVERAGE TEMPERATURE AND IRRADIATION ON

\begin{tabular}{|c|c|c|c|c|c|c|c|c|c|c|c|c|c|}
\hline Month & Jan & Feb & Mar & Apr & May & Jun & Jul & Aug & Sep & Oct & Nov & Dec & Year \\
\hline $\begin{array}{l}I_{\text {opt }}, \mathrm{Wh} / \mathrm{m}^{2} / \\
\text { /day }\end{array}$ & 1200 & 1810 & 2870 & 4100 & 4820 & 4620 & 4710 & 3920 & 3450 & 2320 & 1420 & 887 & 3020 \\
\hline$T,{ }^{\circ} \mathrm{C}$ & 5.7 & 6.0 & 7.1 & 8.5 & 11.1 & 13.7 & 15.7 & 15.8 & 14 & 11.2 & 8.1 & 6.0 & 10.2 \\
\hline
\end{tabular}
OPTIMALLY INCLINED PLATE IN IRELAND [34]

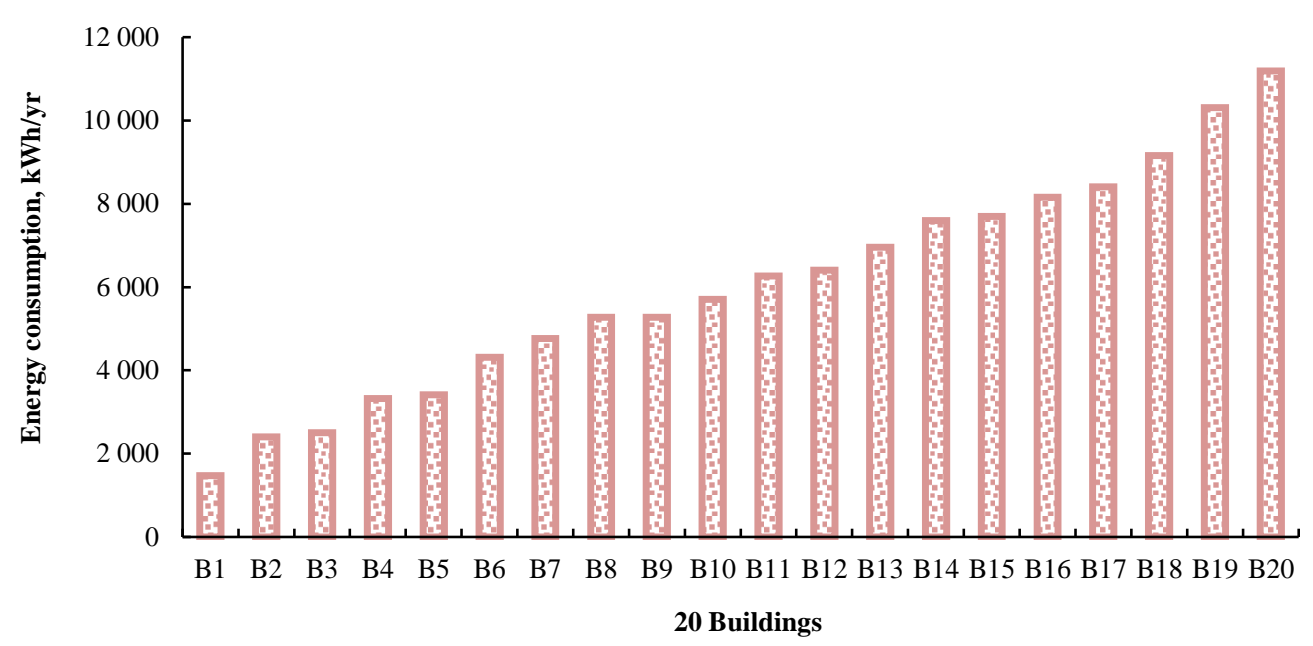

Fig. 4. The annual electricity load of 20 buildings in the community. 


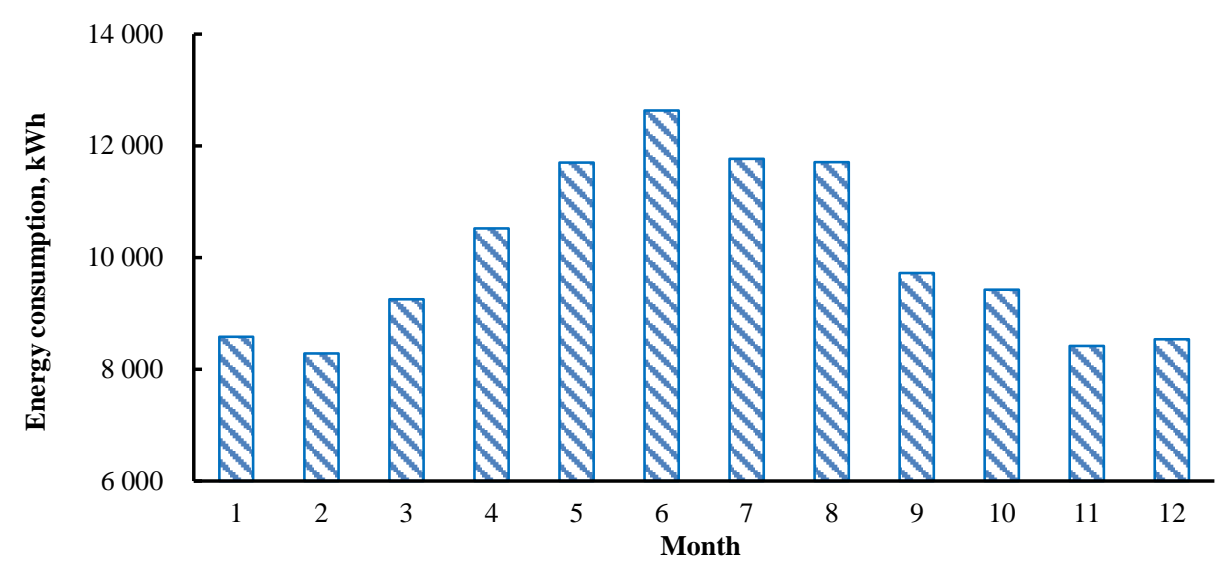

Fig. 5. The electricity load of the entire community in each month.

\subsection{Economic Cost under RPM}

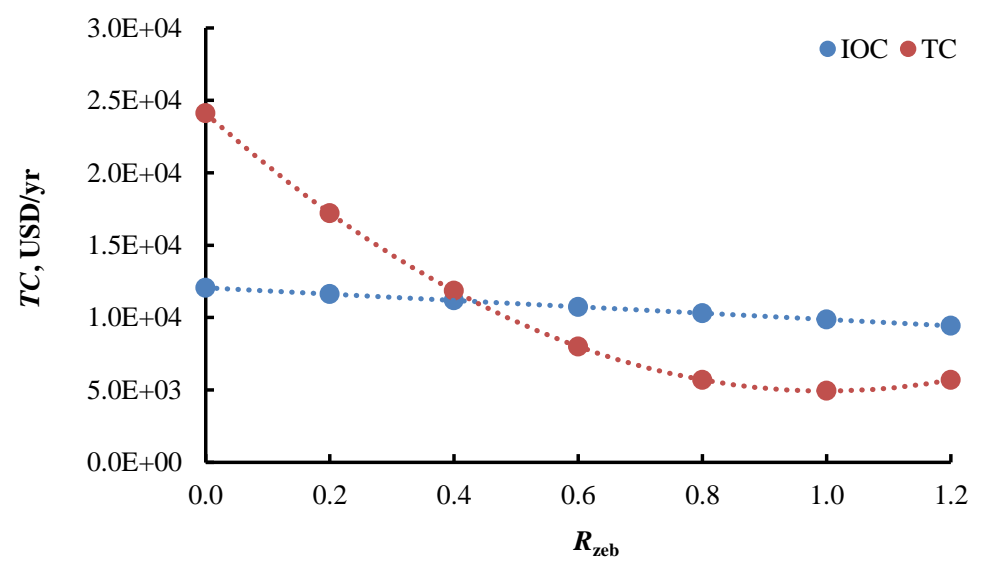

Fig. 6. The total cost of the community under ZEC level selected.

Based on the electricity consumption data of 20 family-houses, the reward-penalty function at community level is solved, i.e., $C_{\mathrm{rp}}=191.801 \cdot R_{\mathrm{zec}}{ }^{2}-36.171 \cdot R_{\mathrm{zec}}+12.057$. The total cost is therefore represented as: $T C=19.181 \cdot R_{\mathrm{zec}}{ }^{2}-38.361 \cdot R_{\mathrm{zec}}+24.114$. The effect of applying community-level RPM on the total cost of the community is reflected as shown in Fig. 6. It can be observed that the developed RPM reshapes the original cost curve into a significant descending concave curve. The maximum value of the total cost is $24114 \mathrm{USD} / \mathrm{yr}$ under a selection of 0.0ZEC design, which is twice time of the traditional buildings without RES system. By contrast, the minimum value of the total cost is $4934 \mathrm{USD} / \mathrm{yr}$ under a selection of $1.0 \mathrm{ZEC}$, which is only half of that in traditional community without RES system. The developed RPM for the community is demonstrated efficient from the reshaped total cost of the community. That is to say, a great profit can be expected for a community at 1.0ZEC design whilst a significant fine will be paid at a lower ZEC level design. 


\subsection{Economic Cost under 1.0ZEC Design}

Under ideal condition, the annual total cost of the community is $4934 \mathrm{USD} / \mathrm{yr}$ at a selection of 1.0ZEC design, which considers PV reliability of 1.0 as time passes. However, this is not the real case and the reliability of PV system is usually decreased with time. Since the reliability of PV system has a great impact on power generation, the level of zero energy community is changing year by year, resulting in an increasing total cost as shown in Fig. 7. The total cost of the community at 1.0ZEC design is observed to be $5005 \mathrm{USD} / \mathrm{yr}$ in the first year, which increases to $6718 \mathrm{USD} / \mathrm{yr}$ in the $10^{\text {th }}$ year, $9767 \mathrm{USD} / \mathrm{yr}$ in the $20^{\text {th }}$ year and $11341 \mathrm{USD} / \mathrm{yr}$ in the $25^{\text {th }}$ year, and the average annual cost is supposed to be $7774 \mathrm{USD} / \mathrm{yr}$.

Accordingly, the total cost is then allocated for each building, as shown in Fig. 8 and Table 3. The cost of each building also increases with years. For instance, the cost of $1^{\text {st }}$ Building (B1) is $61 \mathrm{USD} / \mathrm{yr}$ in the $1^{\text {st }}$ year and increases to $139 \mathrm{USD} / \mathrm{yr}$ in the $25^{\text {th }}$ year, its average annual cost is identified to be $95 \mathrm{USD} / \mathrm{yr}$. By contrast, the cost of $20^{\text {th }}$ Building (B20) is $465 \mathrm{USD} / \mathrm{yr}$ in the $1^{\text {st }}$ year and increases to $1053 \mathrm{USD} / \mathrm{yr}$ in the $25^{\text {th }}$ year, its average annual cost is identified to be $722 \mathrm{USD} / \mathrm{yr}$. In general, the total cost of each building in the $25^{\text {th }}$ year is more than twice that in the $1^{\text {st }}$ year.

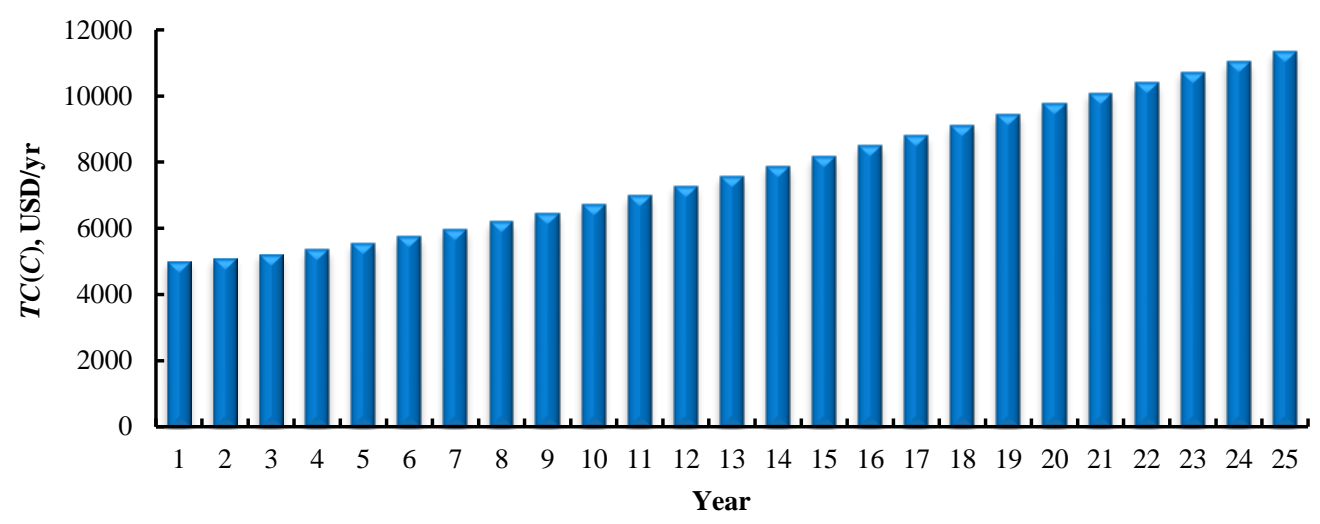

Fig. 7. The total cost of the community under 1.0ZEC design considering PV reliability.

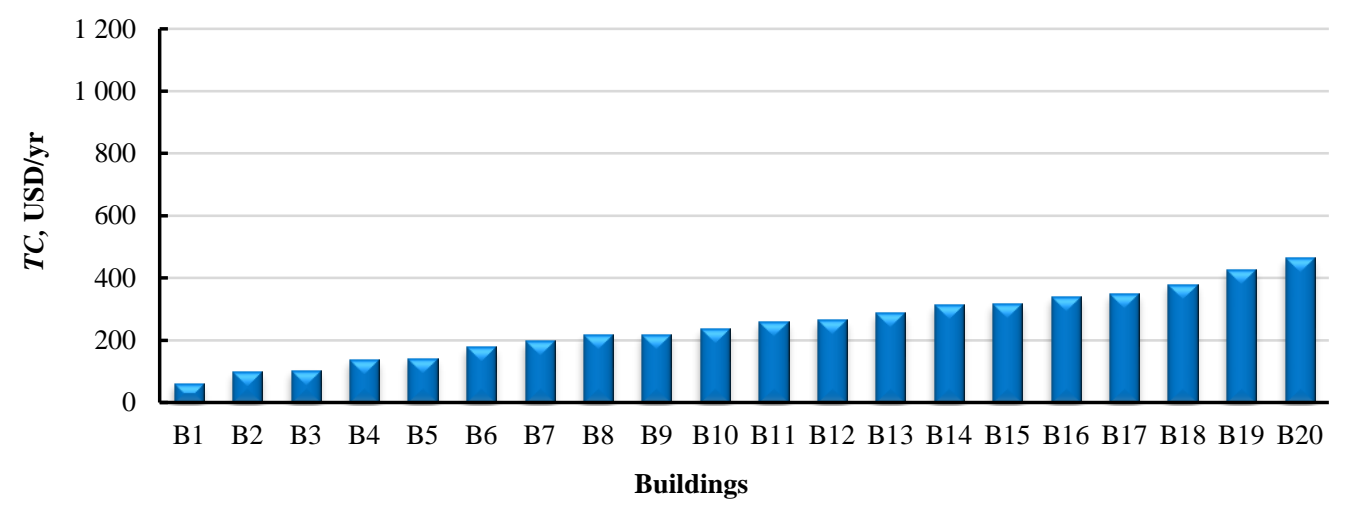

(a) 


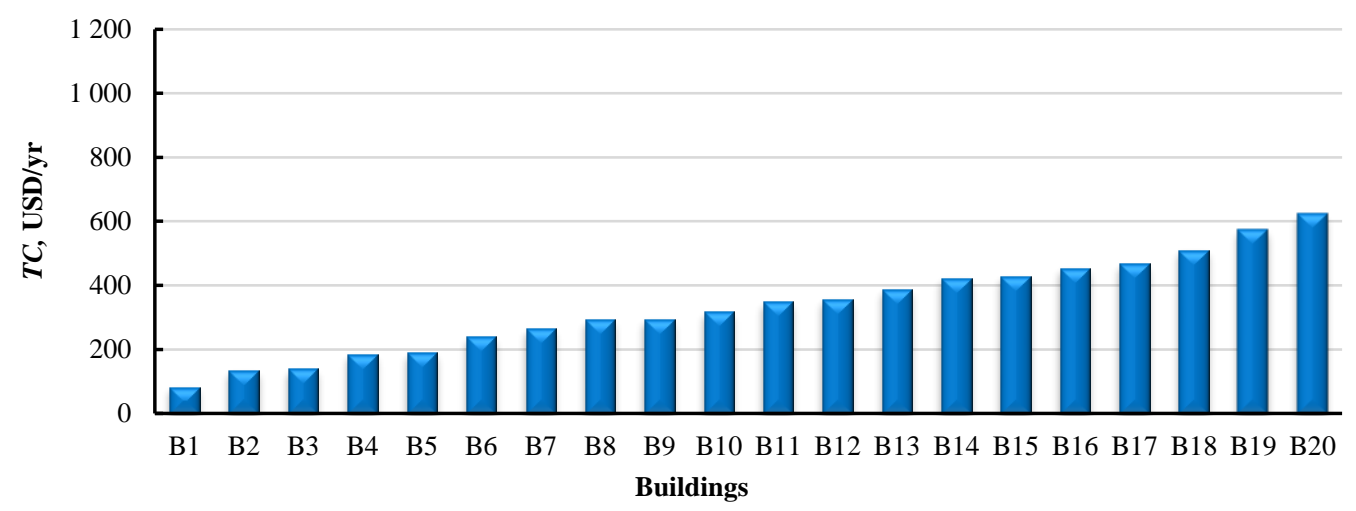

(b)

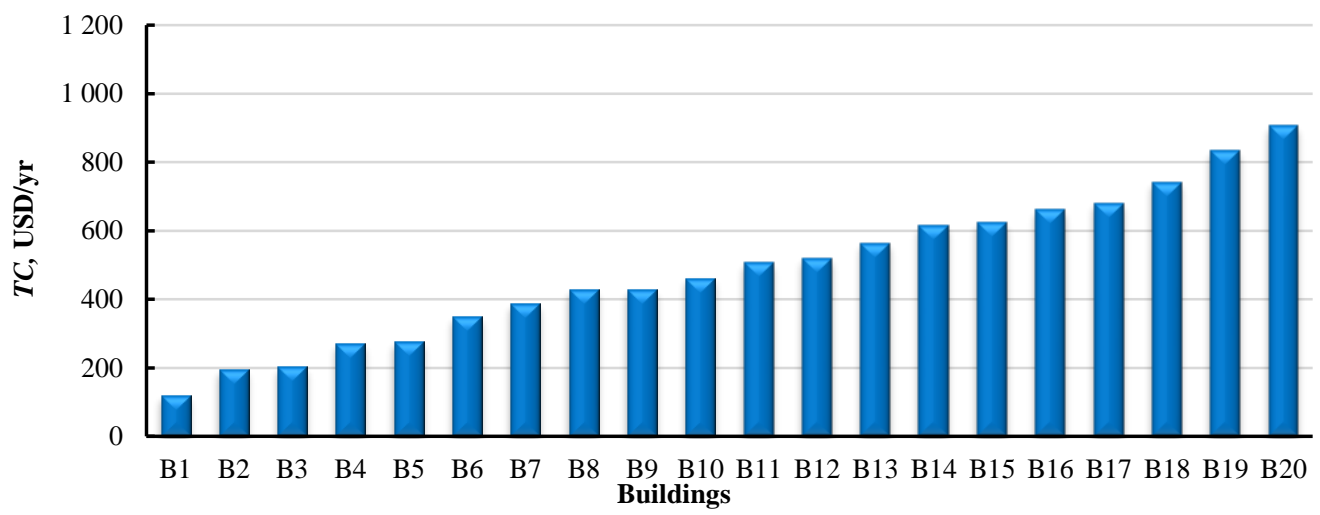

(c)

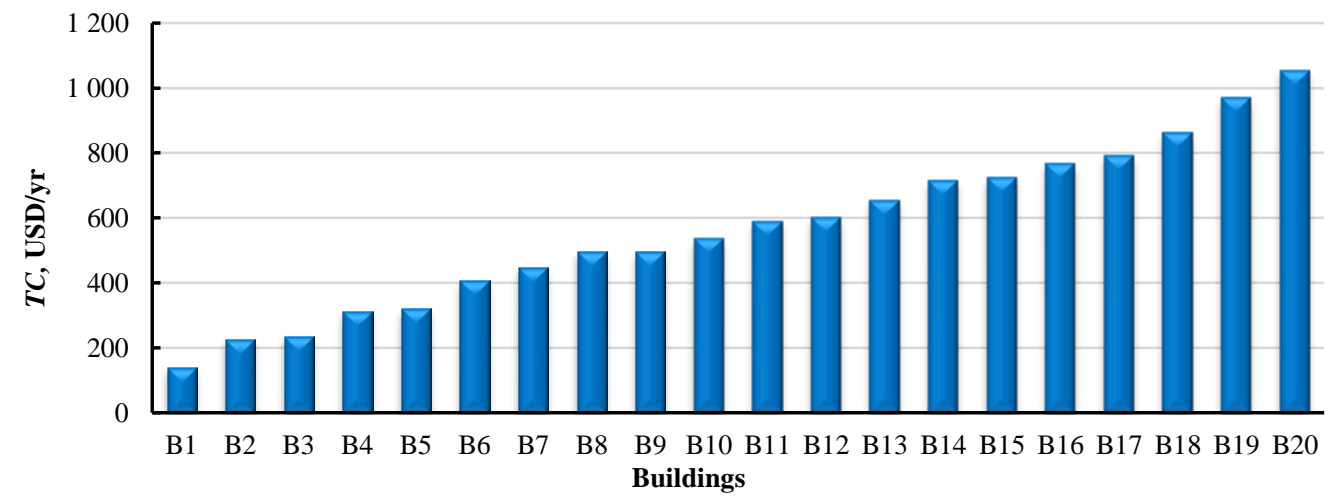

(d)

Fig. 8. The cost allocated for each building in (a) $1^{\text {st }}$ year, (b) $10^{\text {th }}$ year, (c) $20^{\text {th }}$ year and (d) $25^{\text {th }}$ year considering PV reliability. 
TABle 3. The Cost Allocated For EACH BuILdING UNDER 1.0ZEC DESIGN (UNIT: USD/YR)

\begin{tabular}{llllllllll}
\hline $\mathbf{2 0}$ Buildings & Load, $\mathbf{k W h} / \mathbf{y r}$ & $\mathbf{1}^{\text {st }}$ & $\mathbf{5}^{\text {th }}$ & $\mathbf{9}^{\text {th }}$ & $\mathbf{1 3}^{\text {th }}$ & $\mathbf{1 7}^{\text {th }}$ & $\mathbf{2 1}^{\text {st }}$ & $\mathbf{2 5}^{\text {th }}$ & Average \\
\hline B1 & 1476 & 61 & 68 & 79 & 93 & 108 & 123 & 139 & 95 \\
B2 & 2403 & 100 & 110 & 128 & 151 & 175 & 201 & 226 & 155 \\
B3 & 2503 & 104 & 115 & 134 & 157 & 183 & 209 & 235 & 161 \\
B4 & 3319 & 138 & 153 & 177 & 208 & 242 & 277 & 312 & 214 \\
B5 & 3412 & 142 & 157 & 182 & 214 & 249 & 285 & 321 & 220 \\
B6 & 4312 & 179 & 198 & 231 & 271 & 315 & 360 & 406 & 278 \\
B7 & 4761 & 198 & 219 & 255 & 299 & 348 & 398 & 448 & 307 \\
B8 & 5275 & 219 & 242 & 282 & 331 & 385 & 441 & 496 & 340 \\
B9 & 5278 & 219 & 243 & 282 & 332 & 385 & 441 & 496 & 340 \\
B10 & 5704 & 237 & 262 & 305 & 358 & 416 & 477 & 537 & 368 \\
B11 & 6261 & 260 & 288 & 335 & 393 & 457 & 523 & 589 & 404 \\
B12 & 6404 & 266 & 294 & 343 & 402 & 467 & 535 & 602 & 413 \\
B13 & 6960 & 289 & 320 & 372 & 437 & 508 & 582 & 655 & 449 \\
B14 & 7595 & 315 & 349 & 406 & 477 & 554 & 635 & 714 & 490 \\
B15 & 7692 & 319 & 354 & 411 & 483 & 561 & 643 & 724 & 496 \\
B16 & 8157 & 339 & 375 & 436 & 512 & 595 & 682 & 767 & 526 \\
B17 & 8406 & 349 & 386 & 450 & 528 & 614 & 703 & 791 & 542 \\
B18 & 9154 & 380 & 421 & 490 & 575 & 668 & 765 & 861 & 590 \\
B19 & 10305 & 428 & 474 & 551 & 647 & 752 & 862 & 969 & 664 \\
B20 & 11191 & 465 & 514 & 599 & 703 & 817 & 936 & 1053 & 722 \\
Community & 120568 & 5005 & 5542 & 6448 & 7574 & 8800 & 10080 & 11341 & 7774 \\
\hline & & & & & & & & & \\
\hline
\end{tabular}

\subsection{Economic Cost under 1.2ZEC Design}

Since the reliability of PV system decreases with time, a selection of ZEC level is expected to be higher than 1.0ZEC for a community. Therefore, the economic cost under 1.2ZEC design is further investigated and compared with the case under 1.0ZEC design. As shown in Fig. 9, the total cost of the community is first seen to decrease and then increase as time passes. For instance, the total cost is observed to be $5243 \mathrm{USD} / \mathrm{yr}$ in the first year, which increases to $5462 \mathrm{USD} / \mathrm{yr}$ in the $10^{\text {th }}$ year, 8039 $\mathrm{USD} / \mathrm{yr}$ in the $20^{\text {th }}$ year and $9607 \mathrm{USD} / \mathrm{yr}$ in the $25^{\text {th }}$ year. The average annual cost is supposed to be $6548 \mathrm{USD} / \mathrm{yr}$, which is reduced by $15.8 \%$ compared with that under 1.0ZEC design (7 $774 \mathrm{USD} / \mathrm{yr})$.

Similarly, the total cost allocated for each building is also increased with time, as shown in Fig. 10 and Table 4. For instance, the cost of $1^{\text {st }}$ Building (B1) is 64 USD/yr in the $1^{\text {st }}$ year and increases to $118 \mathrm{USD} / \mathrm{yr}$ in the $25^{\text {th }}$ year, and the average annual cost is identified to reduce from $95 \mathrm{USD} / \mathrm{yr}$ under 1.0ZEC design to $80 \mathrm{USD} / \mathrm{yr}$ under 1.2ZEC design. By contrast, the cost of $20^{\text {th }}$ Building (B20) is $487 \mathrm{USD} / \mathrm{yr}$ in the $1^{\text {st }}$ year and increases to $892 \mathrm{USD} / \mathrm{yr}$ in the $25^{\text {th }}$ year, and the average annual cost is identified to reduce from 722 USD/yr under 1.0ZEC design to $608 \mathrm{USD} / \mathrm{yr}$ under 1.2ZEC design. In general, the total cost of each building, as well as the community, is less than that under 1.0ZEC design. 


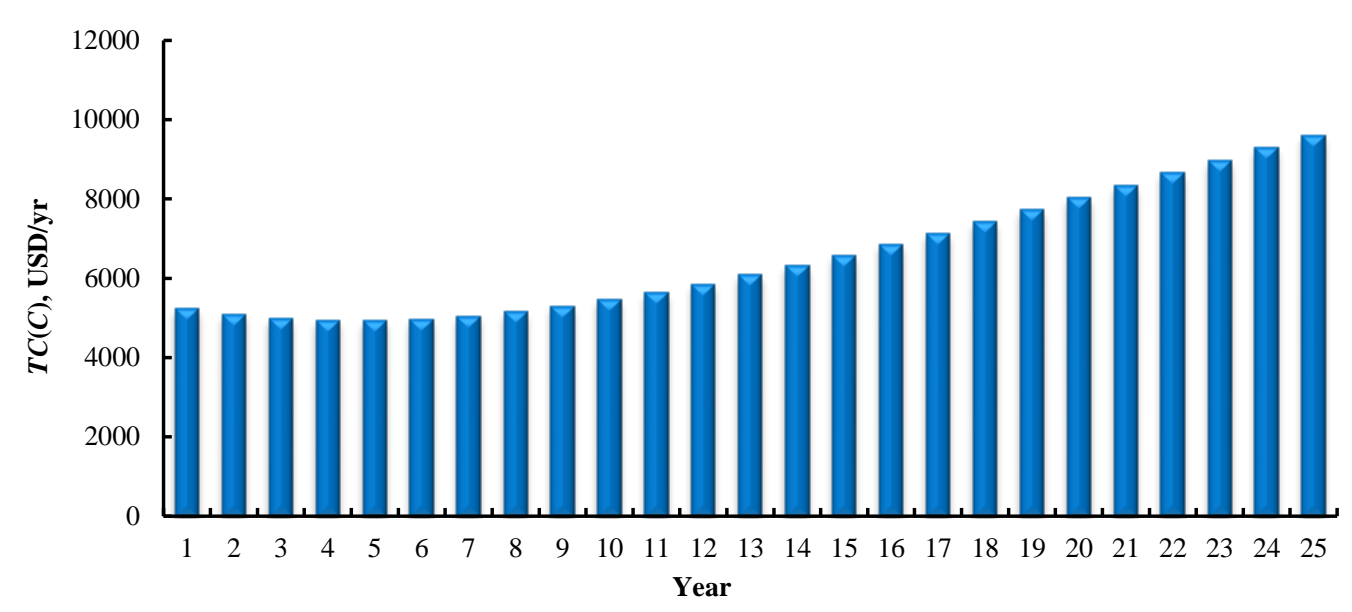

Fig. 9. The total cost of the community under 1.2ZEC design considering PV reliability.

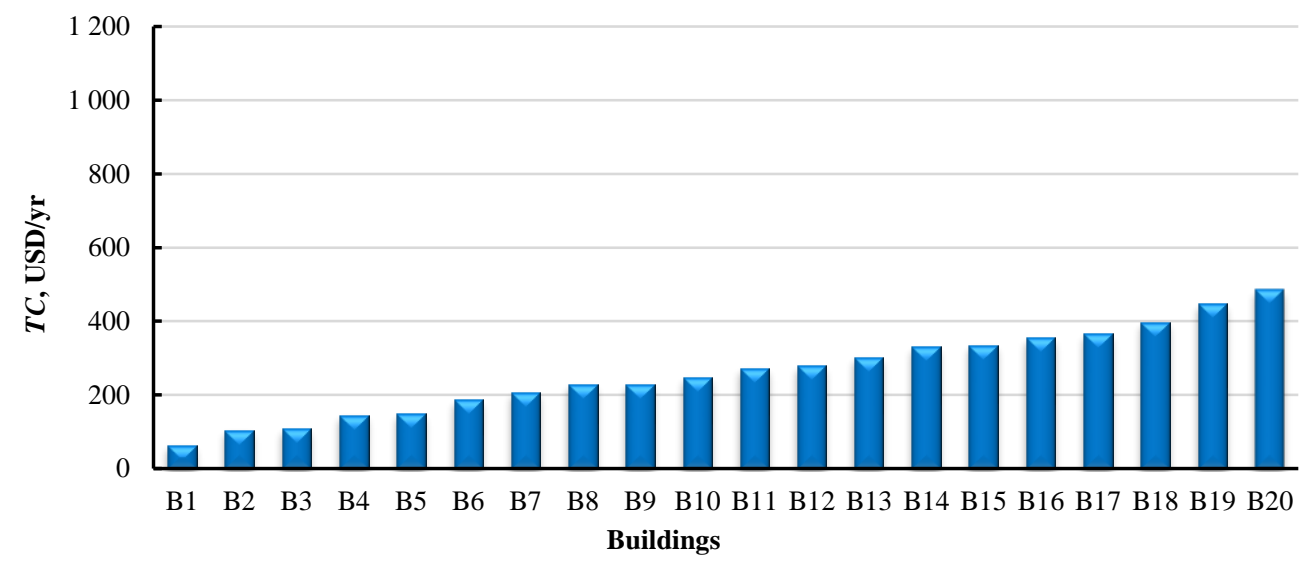

(a)

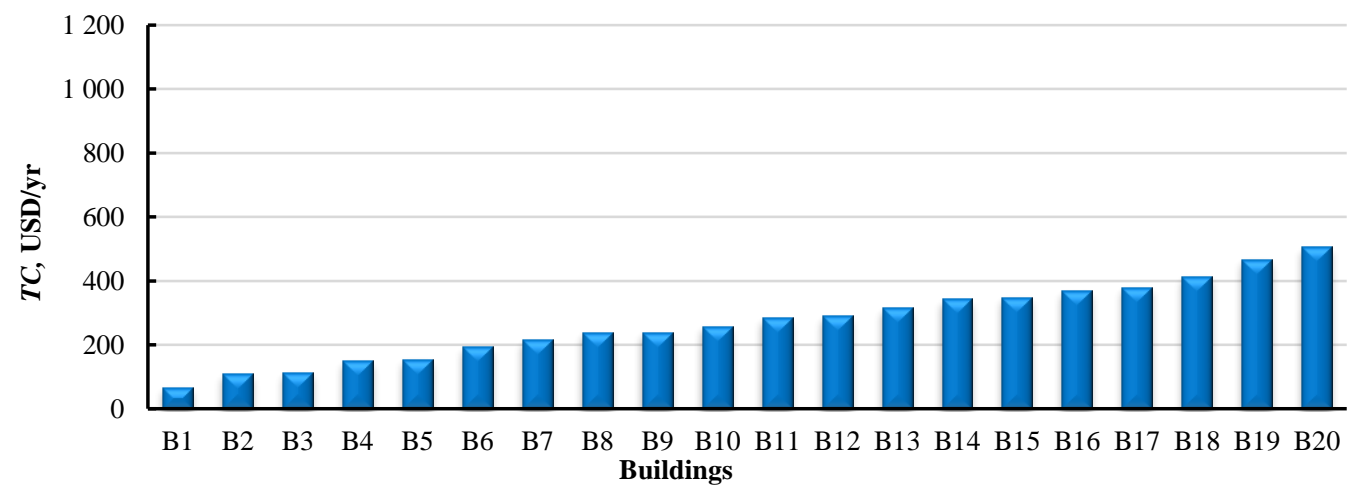

(b) 


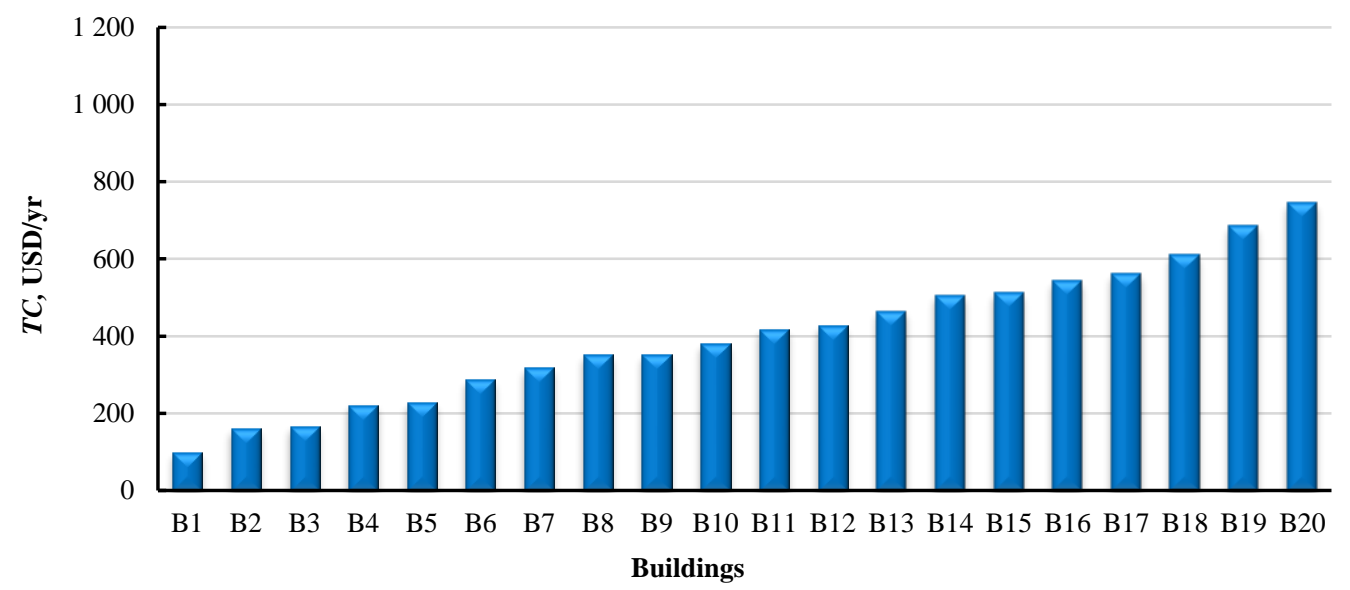

(c)

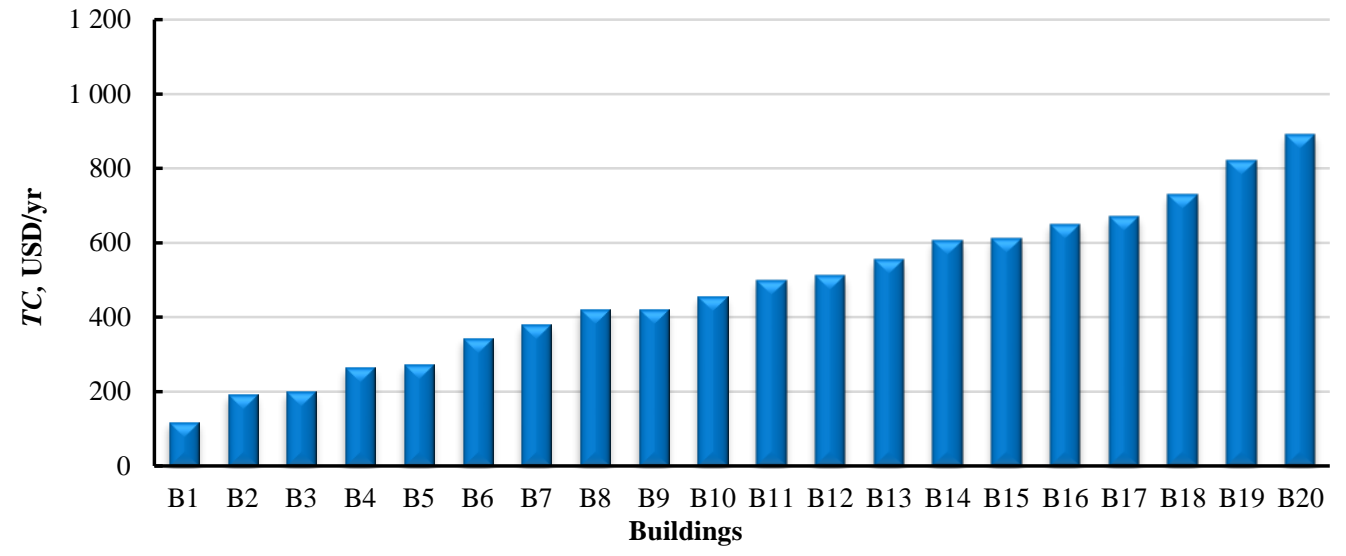

(d)

Fig. 10. The cost allocated for each building in (a) $1^{\text {st }}$ year, (b) $10^{\text {th }}$ year, (c) $20^{\text {th }}$ year and (d) $25^{\text {th }}$ year considering PV reliability. 
TABle 4. The Cost Allocated For EACH BuILding Under 1.2ZEC Design (UnIT: USD/YR)

\begin{tabular}{|c|c|c|c|c|c|c|c|c|c|}
\hline 20 Buildings & Load, kWh/yr & $1^{\text {st }}$ & $5^{\text {th }}$ & $9^{\text {th }}$ & $13^{\text {th }}$ & $17^{\text {th }}$ & $21^{\text {st }}$ & $25^{\text {th }}$ & Average \\
\hline B1 & 1476 & 64 & 60 & 65 & 75 & 87 & 102 & 118 & 80 \\
\hline B2 & 2403 & 104 & 98 & 106 & 121 & 142 & 166 & 191 & 130 \\
\hline B3 & 2503 & 109 & 102 & 110 & 126 & 148 & 173 & 199 & 136 \\
\hline B4 & 3319 & 144 & 136 & 146 & 168 & 196 & 230 & 264 & 180 \\
\hline B5 & 3412 & 148 & 140 & 150 & 172 & 202 & 236 & 272 & 185 \\
\hline B6 & 4312 & 187 & 177 & 189 & 218 & 255 & 298 & 344 & 234 \\
\hline B7 & 4761 & 207 & 195 & 209 & 240 & 282 & 329 & 379 & 259 \\
\hline B8 & 5275 & 229 & 216 & 232 & 266 & 312 & 365 & 420 & 287 \\
\hline B9 & 5278 & 229 & 216 & 232 & 266 & 312 & 365 & 421 & 287 \\
\hline B10 & 5704 & 248 & 234 & 251 & 288 & 338 & 395 & 455 & 310 \\
\hline B11 & 6261 & 272 & 256 & 275 & 316 & 371 & 433 & 499 & 340 \\
\hline B12 & 6404 & 278 & 262 & 281 & 323 & 379 & 443 & 510 & 348 \\
\hline B13 & 6960 & 303 & 285 & 306 & 351 & 412 & 482 & 555 & 378 \\
\hline B14 & 7595 & 330 & 311 & 334 & 383 & 449 & 526 & 605 & 412 \\
\hline B15 & 7692 & 334 & 315 & 338 & 388 & 455 & 532 & 613 & 418 \\
\hline B16 & 8157 & 355 & 334 & 358 & 412 & 483 & 564 & 650 & 443 \\
\hline B17 & 8406 & 366 & 344 & 369 & 424 & 497 & 582 & 670 & 457 \\
\hline B18 & 9154 & 398 & 375 & 402 & 462 & 542 & 633 & 729 & 497 \\
\hline B19 & 10305 & 448 & 422 & 453 & 520 & 610 & 713 & 821 & 560 \\
\hline B20 & 11191 & 487 & 458 & 491 & 565 & 662 & 774 & 892 & 608 \\
\hline Community & 120568 & 5243 & 4938 & 5295 & 6087 & 7135 & 8343 & 9607 & 6548 \\
\hline
\end{tabular}

\section{Conclusion}

This study investigates the economic performance of a net-zero energy community (ZEC) under the proposed reward-penalty mechanism (RPM) by considering PV system reliability. A case study is conducted based on a community consisting of 20 family houses in Ireland. The proposed RPM can bring a great profit for the community under a selection of a higher zero energy level, while a heavy fine will be required for the community with a selection of a lower zero energy level.

The aging effect of PV system is observed to have a significant negative impact on total cost for both the community and its buildings. In terms of 1.0ZEC design, the total cost of the community is $5005 \mathrm{USD} / \mathrm{yr}$ in the first year and increases to $11341 \mathrm{USD} / \mathrm{yr}$ in the $25^{\text {th }}$ year, while the average annual cost is supposed to be $7774 \mathrm{USD} / \mathrm{yr}$. In terms of $1.2 \mathrm{ZEC}$ design, the total cost of the community is $5243 \mathrm{USD} / \mathrm{yr}$ in the first year and increases to 9607 $\mathrm{USD} / \mathrm{yr}$ in the $25^{\text {th }}$ year, while the average annual cost is supposed to be $6548 \mathrm{USD} / \mathrm{yr}$. Thus, 
further investigation will be conducted on the development of enhanced RPM by considering system reliability.

\section{ACKNOWLEDGEMENT}

It is acknowledged that this project received funding from the National Natural Science Foundation of China (Project No. 51608001 and 51478001) to carry out the research work reported in this paper. The authors also acknowledge support provided by the China Scholarship Council (CSC) and research support from the University of Birmingham, United Kingdom.

\section{REFERENCES}

[1] Sun Y., et al. Building-group-level performance evaluations of net zero energy buildings with non-collaborative controls. Applied Energy 2018:212:565-576. doi:10.1016/j.apenergy.2017.11.076

[2] Albatayneh A., et al. The significance of building design for the climate. Environmental and Climate Technologies 2018:22(1):165-178. doi:10.2478/rtuect-2018-0011

[3] Dobson D. W., et al. Sustainable construction: analysis of its costs and benefits. American Journal of Civil Engineering and Architecture 2013:1(2):32-38. doi:10.12691/ajcea-1-2-2

[4] Hussin J. M., et al. The way forward in sustainable construction: issues and challenges. International Journal of Advanced and Applied Sciences 2013:2(1):15-24. doi:10.11591/ijaas.v2i1.1321

[5] Nwokoro I., Onukwube H. N. Sustainable or green construction in Lagos, Nigeria: principles, attributes and framework. Journal of Sustainable Development 2011:4(4):166. doi:10.5539/jsd.v4n4p166

[6] Dania A. A., Larsen G. D., Yao R. Mainstreaming sustainable construction: case studies of an indigenous and multinational firm in Nigeria, 2013.

[7] Miezis M., et al. Climate change and buildings energy efficiency-the key role of residents. Environmental and Climate Technologies 2016:17(1):30-43. doi:10.1515/rtuect-2016-0004

[8] Kemmerer F., Thiagarajan S. Incentive systems. Handbook of human performance technology. San Francisco, CA: Jossey-Bass, 1992.

[9] Taylor J. M. Sustainable building practices: legislative and economic incentives, 2011.

[10] Azis S. S. A., Sipan I., Sapri M. The potential of implementing property tax incentives on green building in Malaysia. American Journal of Economy 2013:3(2):63-67.

[11] Yang D., et al. Green financial policies and capital flows. Physica A: Statistical Mechanics and its Applications 2019:522:135-146. doi.org/10.1016/j.physa.2019.01.126

[12] Choi E. Green on buildings: the effects of municipal policy on green building designations in America's central cities. J Sustain Real Estate 2010:2(1):1-21.

[13] Olubunmi O. A., Xia P. B., Skitmore M. Green building incentives: A review. Renewable and Sustainable Energy Reviews 2016:59:1611-1621. doi.org/10.1016/j.rser.2016.01.028

[14] Tinker A., et al. Green construction: contractor motivation and trends in Austin, Texas. Journal of Green Building 2006:1(2):118-34.

[15] Ibrahim K. I., Costello S. B., Wilkinson S. Key practice indicators of team integration in construction projects: a review. Team Perform Management 2013:19:132-152. doi:10.1108/TPM-10-2012-0033

[16] Rakha T., Moss T. W., Shin D. A decade analysis of residential LEED buildings market share in the United States: Trends for transitioning sustainable societies. Sustainable Cities and Society 2018:39:568-577. doi:10.1016/j.scs.2018.02.040

[17] Cease B., et al. Barriers and incentives for sustainable urban development: An analysis of the adoption of LEED-ND projects. Journal of Environmental Management 2019:244:304-312. doi:10.1016/j.jenvman.2019.04.020

[18] Suzer O. A comparative review of environmental concern prioritization: LEED vs other major certification systems. Journal of Environmental Management 2015:154:266-283. doi:10.1016/j.jenvman.2015.02.029

[19] Alam S. S., et al. A survey on renewable energy development in Malaysia: Current status, problems and prospects. Environmental and Climate Technologies 2016:17(1):5-17. doi:10.1515/rtuect-2016-0002

[20] Javier Ramírez F., et al. Combining feed-in tariffs and net-metering schemes to balance development in adoption of photovoltaic energy: Comparative economic assessment and policy implications for European countries. Energy Policy 2017:102:440-452. doi:10.1016/j.enpol.2016.12.040

[21] Abolhosseini S., Heshmati A. The main support mechanisms to finance renewable energy development. Renewable \& Sustainable Energy Reviews 2014:40:876-885. doi:10.1016/j.rser.2014.08.013

[22] Banovac E., Glavić M, Tešnjak S. Establishing an efficient regulatory mechanism-Prerequisite for successful energy activities regulation. Energy 2009:34(2):178-189. doi:10.1016/j.energy.2008.10.002 
[23] Li L., et al. How will the Chinese Certified Emission Reduction scheme save cost for the national carbon trading system? Journal of Environmental Management 2019:244:99-109. doi:0.1016/j.jenvman.2019.04.100

[24] Primdahl J., et al Current use of impact models for agri-environment schemes and potential for improvements of policy design and assessment. Journal of Environmental Management 2010:91(6):1245-1254. doi:10.1016/j.jenvman.2009.12.012

[25] Lu Y., et al. Penalty-cost-based design optimization of renewable energy system for net zero energy buildings. Energy Procedia 2018:147:7-14. doi:10.1016/j.egypro.2018.07.027

[26] Lu Y., et al. Impact of introducing penalty-cost on optimal design of renewable energy systems for net zero energy buildings. Applied Energy 2019:235:106-116. doi:10.1016/j.apenergy.2018.10.112

[27] Billinton R., Allan R. N. Reliability evaluation of engineering systems- 2nd ed. New York: Springer Science, 1992.

[28] Alvarez-Alvarado M. S., Jayaweera D. Aging Reliability Model for Generation Adequacy. Presented at the 2018 IEEE International Conference on Probabilistic Methods Applied to Power Systems (PMAPS), 24-28 June, USA, 2018.

[29] Bagen. Reliability and Cost/Worth Evaluation of Generating Systems Utilizing Wind and Solar Energy. Thesis. Canada: University of Saskatchewan, 2005.

[30] Alvarez-Alvarado M. S., Jayaweera D. Reliability Model for a Static Var Compensator. Presented at the 2017 IEEE Ecuador Technical Chapters Meeting (ETCM), 16-20 Oct, Ecuador, 2007.

[31] Alvarez-Alvarado M. S., Jayaweera D. A New Approach for Reliability Assessment of a Static Var Compensator Integrated Smart Grid. Presented at the 2018 IEEE International Conference on Probabilistic Methods Applied to Power Systems (PMAPS), 22-26 Jun 2018.

[32] ISSDA, CER Smart Meter Customer Behaviour Trials Data, CER Electricity [Online]. [Accessed 01.03.2012]. Available: www.ucd.ie/issda

[33] Khan Z. A., Jayaweera D., Alvarez-Alvarado M. S. A novel approach for load profiling in smart power grids using smart meter data. Electric Power Systems Research 2018:165:191-198. doi:10.1016/j.epsr.2018.09.013

[34] Appendix A: Irelands Solar Radiation [Online]. Available: https://sites.google.com/site/ee535test/gerard-cahill/appendix-a-ireland-solar-potential. 